\title{
Riqueza de fungos ingoldianos e de fungos aquático-facultativos no Parque Municipal do Carmo, São Paulo, SP, Brasil
}

\author{
밈acema H. Schoenlein-Crusius ${ }^{1,3}$, Carolina Gasch Moreira ${ }^{1}$ e Eduardo Pereira Cabral Gomes ${ }^{2}$
}

Recebido: 12.03.2018; aceito: 18.05.2018

\begin{abstract}
Richness of ingoldian fungi and aquatic facultative fungi in the Parque Municipal do Carmo, São Paulo, São Paulo State, Brazil). The richness of ingoldian fungi, aquatic facultative fungi, and some abiotic variables were evaluated in some lakes and streams of the Parque do Carmo, in the city of São Paulo, in São Paulo State. Monthly collections of submerged mixed leaf samples were carried out from March 2007 to June 2009. Additionally, the temperature, $\mathrm{pH}$, dissolved oxygen and conductivity were measured using a multi-probe. In the laboratory, leaves were washed, divided into fragments $\left(1 \mathrm{~cm}^{2}\right)$, incubated in sterile distilled water $\left(30\right.$ days, $\left.22{ }^{\circ} \mathrm{C}\right)$ and analyzed under microscope for fungal identification by means of the current literature. Thirty-five fungal taxa were obtained, which were divided into 22 ingoldian fungi (more frequent in the streams), and 13 aquatic facultative fungi (more frequent in the lakes). The richness of the mycota in the dry and cold seasons was similar to that of the rainy and hot seasons, but it decreased in the dry and hot periods. The climatic season had a greater influence on fungal richness than the type of collection site, with positive correlations between the mycota, the temperature and the electrical conductivity of the water. The Parque do Carmo presents a considerable richness of ingoldian and aquatic facultative fungi, and offers interesting aquatic environments for studies related to the seasonal climatic influence on the urban aquatic mycota.
\end{abstract}

Keywords: climatic conditions, freshwater fungi, fungal diversity, urban waters

RESUMO - (Riqueza de fungos ingoldianos e de fungos aquático-facultativos no Parque Municipal do Carmo, São Paulo, $\mathrm{SP}$, Brasil). A riqueza de fungos ingoldianos, fungos aquático-facultativos e algumas variáveis abióticas foram avaliadas em alguns lagos e riachos no Parque do Carmo na cidade de São Paulo, SP. Coletas mensais de folhedo misto submerso foram realizadas de março de 2007 a junho de 2009. Adicionalmente, a temperatura, $\mathrm{pH}$, oxigênio dissolvido e a condutividade foram medidos com um equipamento multisonda. No laboratório, as folhas foram lavadas, divididas em fragmentos (1 $\left.\mathrm{cm}^{2}\right)$, incubadas em água destilada esterilizada $\left(30\right.$ dias, $\left.2{ }^{\circ} \mathrm{C}\right)$ e analisadas microscopicamente para identificação dos táxons com base na literatura pertinente. Foram obtidos 35 táxons, divididos em 22 fungos ingoldianos, (mais frequentes nos córregos) e 13 fungos aquático-facultativos (mais frequentes nos lagos). A riqueza da micota nas épocas secas e frias foi semelhante a das épocas chuvosas e quentes, porém diminuiu nas épocas secas e quentes. O tipo de estação climática exerceu maior influência na riqueza de fungos do que o tipo de local de coleta, com correlações positivas entre a micota, a temperatura e a condutividade elétrica da água. O Parque do Carmo apresenta riqueza considerável de fungos ingoldianos e aquático-facultativos, oferecendo ambientes aquáticos interessantes para estudos sobre a influência climática sazonal na micota aquática urbana.

Palavras-chave: águas urbanas, condições climáticas, diversidade fúngica, fungos de água doce

\section{Introdução}

Os fungos ingoldianos reproduzem-se assexuadamente através de conídios de formas hidrodinâmicas tetrarradiadas, esféricas ou sigmoides, sendo aquáticos típicos, geralmente associados a substratos vegetais submersos em riachos ou córregos
(Ingold 1975). Constituem um grupo ecológico e polifilético (Baschien et al. 2006) considerado de grande importância nos processos de decomposição de substratos vegetais e mantém estreita relação com os organismos detritívoros através da cadeia trófica (Bärlocher \& Sridhar 2014). Os fungos aquático-facultativos, que provem de diversos grupos

1. Instituto de Botânica, Núcleo de Pesquisas em Micologia, Caixa Postal 68041, 04045-972 São Paulo, SP, Brasil

2. Instituto de Botânica, Núcleo de Pesquisas em Ecologia, Caixa Postal 68041, 04045-972 São Paulo, SP, Brasil

3. Autor para correspondência: iracema@crusius.com.br 
taxonômicos, são de origem externa à água, porém podem ser reprodutivos e ativos na mesma (Goh \& Hyde 1996). Ambos os grupos são importantes integrantes da micota que atua na decomposição de substratos orgânicos submersos em águas lóticas e lênticas.

O presente estudo faz parte de um projeto de pesquisa mais amplo, no qual levantamentos da micota aquática, composta por fungos ingoldianos e aquáticofacultativos, foram conduzidos em alguns parques municipais na cidade de São Paulo, tais como o Parque Alfredo Volpi (Moreira \& Schoenlein-Crusius 2012), Parque do Ibirapuera (Schoenlein-Crusius et al. 2014), Parque da Aclimação (Schoenlein-Crusius et al. 2015) e Parque Estadual das Fontes do Ipiranga (SchoenleinCrusius et al. 2016), revelando que a diversidade apresenta-se maior do esperado para ambientes sob forte influência antrópica, com espécies reportadas pela primeira vez para o Estado de São Paulo, para o Brasil e até espécies novas para a Ciência.

A revisão recente de Fiuza et al. (2017) indica que os conhecimentos sobre a diversidade dos fungos ingoldianos têm avançado significativamente conforme são realizadas coletas em novos biomas. Além disso, a riqueza destes fungos pode indicar o estado de conservação das águas (Burgos \& Castillo 1986, Gessner et al. 1991), o que no caso de áreas sob considerável influência antrópica tais como são os parques urbanos, é relevante para subsidiar medidas de recuperação tanto das águas quanto da vegetação, oferecendo-se à população áreas de convívio com a natureza de melhor qualidade.

O Parque Municipal do Carmo localiza-se em Itaquera, na zona leste da cidade de São Paulo, sendo de grande importância como área verde para a população local. No século XVII a Ordem do Carmo adquiriu uma extensa área de terras ("Terras de Caguassú") que foi transformada em fazenda para a criação de rebanhos, plantações de chá, café, hortaliças, etc. Após 200 anos a fazenda foi dividida em glebas e em 1976 a Prefeitura de São Paulo adquiriu a fazenda, criando o Parque do Carmo que ocupa uma área de $1.500 .000 \mathrm{~m}^{2}$, sendo o segundo maior parque dentro da região metropolitana. A flora é diversificada havendo pomares, cafezais, capoeiras, brejos, Mata Atlântica, bosques de eucaliptos e um famoso bosque de cerejeiras, mantido pela comunidade japonesa da cidade. Há diversas nascentes que fornecem água para os lagos (Centro de Pesquisas de História Natural, 1988, http://www.prefeitura.sp.gov.br), que são de grande valor paisagístico na área.
O presente artigo tem o objetivo de relatar a riqueza dos fungos ingoldianos e dos aquáticofacultativos no Parque do Carmo, acrescentando algumas variáveis abióticas para fins de registro histórico e verificando se há valores limitantes para a riqueza desses fungos.

\section{Materiais e métodos}

Amostras de folhedo misto submerso (aproximadamente $50 \mathrm{~g}$ cada) foram coletadas, em triplicata, mensalmente de março de 2007 a junho de 2009 em cinco locais, assim descritos: local 1 - Lago das bananeiras $\left(23^{\circ} 34^{\prime} 29,3^{\prime \prime S}\right.$ e $46^{\circ} 27^{\prime} 57,3$ ”W); local 2 - Córrego das bananeiras (2334'28,5'S e 46 27'57,3' 'W); local 3 - Lago Central (2334'22,4”S e $\left.46^{\circ} 27^{\prime} 53,9^{\prime \prime} \mathrm{W}\right)$; local 4 - Lago assoreado (2334'15,3'S e $\left.46^{\circ}{ }^{\circ} 7^{\prime} 58,7^{\prime \prime} \mathrm{W}\right)$ e local 5 - Córrego ao lado da Administração (2334'23.8'S e $\left.46^{\circ} 28^{\prime} 04.9^{\prime \prime} \mathrm{W}\right)$. Durante as coletas foram medidas algumas variáveis abióticas como a temperatura, $\mathrm{pH}$, oxigênio dissolvido e condutividade da água com a multisonda $\mathrm{U}_{10}$ da Horiba.

No laboratório, as folhas foram lavadas sob água corrente, divididas em fragmentos $\left(1 \mathrm{~cm}^{2}\right)$ e incubadas em água destilada esterilizada ( 30 dias, $22^{\circ} \mathrm{C}$ ).

Regularmente, durante o período de 30 dias, alguns desses fragmentos foram dispostos entre lâmina e lamínula com gotas de água destilada esterilizada e analisados sob microscópio de luz à procura de estruturas reprodutivas que permitissem a identificação dos táxons diretamente desenvolvidos sobre as folhas, utilizando literatura pertinente (Ingold 1975, Marvanová 1997, Santos-Flores \& BetancourtLópez 1999). Lâminas semipermanentes preparadas com azul de algodão com lactofenol, seladas com esmalte, foram preservadas à título de documentação dos táxons encontrados.

Os dados meteorológicos de precipitação pluviométrica $(\mathrm{mm})$, número de dias chuvosos, temperaturas médias mensais e umidade relativa (\%) durante o período de estudo foram fornecidos pelo Instituto Astronômico e Geofísico da Universidade de São Paulo e constam detalhadamente em SchoenleinCrusius et al. (2014). Esses dados climáticos caracterizam a época chuvosa e quente como tendo ocorrido no período de outubro de 2007 a fevereiro de 2008 e de outubro de 2008 a março de 2009. Épocas secas e frias ocorreram nos meses de agosto a setembro de 2007 e no mês de julho de 2008. Em julho de 2007 foi registrado o acúmulo de 160,9 mm 
de chuvas, considerado elevado para essa época, considerada chuvosa e fria. Também em abril de 2008, época chuvosa e quente, ocorreu um pico de chuvas, acumulando 121,8 mm naquele mês. Outubro de 2007 e março de 2008 foram caracterizados como meses secos e quentes. A umidade relativa do ar (\%) acompanhou as flutuações da precipitação, variando entre 74,1 e $82,6 \%$ no período estudado.

As medidas de temperatura, $\mathrm{pH}$, condutividade elétrica e teor de oxigênio dissolvido na água foram obtidas em cada local à cada coleta. Diferenças entre os locais de coleta para cada variável abiótica foram testadas por Análise de Variância de um fator, desde que as premissas do teste fossem satisfeitas. Quando não, o teste não-paramétrico correspondente, teste de Kruskal-Wallis, foi utilizado.

A partir do número de fungos facultativos e ingoldianos foram construídas duas matrizes: a primeira do número de ocorrências de fungos por local de coleta e a segunda o número de ocorrência de fungos por data de coleta.

A correlação múltipla tanto dos dados bióticos como as ocorrências de fungos ingoldianos e dos facultativos, quanto dos abióticos foi testada. $\mathrm{Na}$ ausência de distribuição normal dos dados foi feito o teste não-paramétrico de correlação de Spearman.

As 24 datas de coleta foram ordenadas pela temperatura e precipitação acumulada, nos 30 dias que antecederam a coleta, sendo classificados em: quente e seco - QS(QS1 para o local 1, QS2 para o local $2, \ldots$.$) ; quente e chuvosa - QU; fria e seca - FS;$ fria e chuvosa - FU. A partir da matriz da frequência de registros de fungos por local e época foi calculada a matriz de distância de corda e desta feita a ordenação por Análise de Coordenadas Principais (PCoA, Borg \& Groenen 2005).

\section{Resultados}

Os valores de temperatura (tabela 1) foram significativamente diferentes entre os locais $3 \mathrm{e}$ 5 (ANOVA 1 fator, $\mathrm{F}=5,46, \mathrm{p}<0,001$ ). $\mathrm{O}$ maior valor médio da temperatura da água foi registrado em dezembro de 2007 , correspondendo a $24,6{ }^{\circ} \mathrm{C}$ e a menor em junho de $2008,15,6^{\circ} \mathrm{C}$.

Os valores médios do $\mathrm{pH}$ da água (tabela 1 ) não apresentaram diferenças estatisticamente significativas entre os locais de coleta (teste de Kruskal-Wallis, $\mathrm{H}=8,98, \mathrm{p}>0,05$ ), variando de 6,18 (local 4) a 6,63 (local 5). Em novembro de 2007 foi registrado o maior valor médio do $\mathrm{pH}$, correspondente a 7,57 e em julho de 2008 , o menor valor, equivalente a 3,85 .
Para as medidas de condutividade (tabela 1) todos os pontos de coleta diferiram entre si (teste de Kruskal-Wallis, $\mathrm{H}=84,49, \mathrm{p}<0,0001$ ), exceto 1 com 2 e 3 com 5 . Em outubro de 2008 foi registrada a maior média correspondente a 0,054 e em maio de 2007, a menor média, equivalente a $0,025 \mu \mathrm{Scm}^{-3}$.

Os teores de oxigênio dissolvido (tabela 1) apresentaram diferenças estatisticamente significativas entre todos os locais de coleta, exceto os locais 1 e 4 (teste de Kruskal-Wallis, $\mathrm{H}=83,01, \mathrm{p}<0,0001$ ). No local 4 os valores individuais medidos de oxigênio dissolvido apresentaram a tendência de serem os mais baixos, chegando a valores críticos como $1,30 \mathrm{mgO}_{2} \cdot \mathrm{L}^{-1} \mathrm{em}$ fevereiro de 2008 e $1,50 \mathrm{mgO}_{2} \cdot \mathrm{L}^{-1}$ em janeiro de 2008. A menor média, correspondente a $0,79 \mathrm{mgO}_{2} \cdot \mathrm{L}^{-1}$ ocorreu em maio de 2007 e a maior, equivalente a $6,74 \mathrm{mgO}_{2} \cdot \mathrm{L}^{-1}$, em junho de 2009.

A ocorrência dos táxons dos fungos ingoldianos e dos aquático-facultativos isolados do Parque do Carmo foram agrupados de acordo com a caracterização climática dos meses de coleta (tabelas 2 a 5). Foram obtidos 35 táxons de fungos, distribuídos em 108 ocorrências totais no período estudado. No total foram registrados 22 fungos ingoldianos e 13 táxons de fungos aquático-facultativos.

Os táxons que predominaram no presente estudo foram os ingoldianos Triscelophorus monosporus Ingold (8 registros em 10 ocorrências), Margaritispora aquatica Ingold (6 registros em 10 ocorrências), Anguillospora crassa Ingold (6 registros em 10 ocorrências) e Tripospermum myrti (Lind.) S.J. Hughes (6 registros em 9 ocorrências).

Os demais táxons ocorreram com menor número de registros ou ocorrências, ou ainda se fizeram presentes nas amostras de forma esporádica. Entre os fungos aquático-facultativos, os mais frequentes foram, Alternaria alternata (Fr. Keissl.), Fusarium sp. e Pestalotiopsis sp., presentes em três meses do período das coletas. Cylindrocladium scoparium Morgan foi registrado somente em fevereiro e março de 2009, porém em vários locais de coleta, somando seis ocorrências.

Nos meses secos e frios (tabela 2) foram obtidos 12 táxons (26 ocorrências) de fungos ingoldianos e sete (15 ocorrências) dos aquáticofacultativos. Julho de 2008 destacou-se como mês seco e frio com maior número de fungos ingoldianos, somando quatro táxons, agosto de 2008 apresenta seis ocorrências decorrentes da presença de Margaritispora aquática Ingold em todos os locais de coleta. Ocorrendo de maneira mais esparsa, mas 
Tabela 1. Valores individuais e médios da temperatura $\left({ }^{\circ} \mathrm{C}\right), \mathrm{pH}$, condutividade elétrica $\left(\mu \mathrm{Scm}^{-3}\right)$ e oxigênio dissolvido $\left(\mathrm{mgO}_{2} \cdot \mathrm{L}^{-1}\right)$ da água, no Parque Municipal do Carmo, São Paulo, SP, Brasil. Médias seguidas de mesma letra não diferiram entre si.

Table 1. Individual and mean values of temperature $\left({ }^{\circ} \mathrm{C}\right), \mathrm{pH}$, electric conductivity $\left(\mu \mathrm{Scm}^{-3}\right)$ and dissolved oxygen $\left(\mathrm{mgO}_{2} \cdot \mathrm{L}^{-1}\right)$ of the water in the Parque Municipal do Carmo, São Paulo, São Paulo State, Brazil. Means followed by same letter did not differ.

\begin{tabular}{|c|c|c|c|c|c|c|c|}
\hline \multicolumn{8}{|c|}{ Temperatura } \\
\hline Coletas & datas & Local 1 & Local 2 & Local 3 & Local 4 & Local 5 & Médias \\
\hline $1^{\mathrm{a}}$ & 28.05 .07 & 17,1 & 16,7 & 18,0 & 16,6 & 16,6 & 17,0 \\
\hline $2^{\mathrm{a}}$ & 04.07 .07 & 17,0 & 16,0 & 19,1 & 17,0 & 15,8 & 17,0 \\
\hline $3^{\mathrm{a}}$ & 24.08 .07 & 22,3 & 19,5 & 25,5 & 22,1 & 18,1 & 21,5 \\
\hline $4^{\mathrm{a}}$ & 05.10 .07 & 24,3 & 21,0 & 26,8 & 23,4 & 19,3 & 22,9 \\
\hline $5^{\mathrm{a}}$ & 28.11 .07 & 26,5 & 22,3 & 26,3 & 26,9 & 19,3 & 24,3 \\
\hline $6^{\mathrm{a}}$ & 27.12 .07 & 26,0 & 24,0 & 26,0 & 26,0 & 21,0 & 24,6 \\
\hline $7^{\mathrm{a}}$ & 22.01 .08 & 20,0 & 21,0 & 22,0 & 21,0 & 19,0 & 20,6 \\
\hline $8^{\mathrm{a}}$ & 19.02 .08 & 24,0 & 23,0 & 26,0 & 23,0 & 21,0 & 23,4 \\
\hline $9^{\mathrm{a}}$ & 12.03 .08 & 25,0 & 24,0 & 25,0 & 25,0 & 23,0 & 24,4 \\
\hline $10^{\mathrm{a}}$ & 22.04 .08 & 22,0 & 21,0 & 23,0 & 21,0 & 20,0 & 21,4 \\
\hline $11^{\mathrm{a}}$ & 12.05 .08 & 17,4 & 17,3 & 18,0 & 16,7 & 16,4 & 17,2 \\
\hline $12^{\mathrm{a}}$ & 25.06 .08 & 16,0 & 16,0 & 16,0 & 15,0 & 15,0 & 15,6 \\
\hline $13^{\mathrm{a}}$ & 23.07 .08 & 17,3 & 16,6 & 18,4 & 15,4 & 16,5 & 16,8 \\
\hline $14^{\mathrm{a}}$ & 28.08 .08 & 18,6 & 18,7 & 20,7 & 18,7 & 16,7 & 18,7 \\
\hline $15^{\mathrm{a}}$ & 24.09 .08 & 18,7 & 18,0 & 19,5 & 17,9 & 16,2 & 18,1 \\
\hline $16^{\mathrm{a}}$ & 29.10 .08 & 22,4 & 21.8 & 23,6 & 22,5 & 19,1 & 21,9 \\
\hline $17^{\mathrm{a}}$ & 18.11 .08 & 22,0 & 21,0 & 23,2 & 21,3 & 18,7 & 21,2 \\
\hline $18^{\mathrm{a}}$ & 17.12 .08 & 21,9 & 21,3 & 23,8 & 22,3 & 18,9 & 21,6 \\
\hline $19^{\mathrm{a}}$ & 27.01 .09 & 23,4 & 22,9 & 24,7 & 23,4 & 20,3 & 22,9 \\
\hline $20^{\mathrm{a}}$ & 26.02 .09 & 23,5 & 22,3 & 25,9 & 22,4 & 21,0 & 23,0 \\
\hline $21^{\mathrm{a}}$ & 24.03 .09 & 22,8 & 22,4 & 23,8 & 22,3 & 20,1 & 22,3 \\
\hline $22^{\mathrm{a}}$ & 28.04 .09 & 21,2 & 20,1 & 22,4 & 20,0 & 18,6 & 20,5 \\
\hline $23^{\mathrm{a}}$ & 26.05 .09 & 19,6 & 19,2 & 22,0 & 19,1 & 18,5 & 19,7 \\
\hline $24^{\mathrm{a}}$ & 23.06 .09 & 16,3 & 16,0 & 17,5 & 14,8 & 15,1 & 15,9 \\
\hline Médias & & $21,1^{\mathrm{ab}}$ & $20,0^{\mathrm{ab}}$ & $22,4^{a}$ & $20,6^{\mathrm{ab}}$ & $18,5^{\mathrm{b}}$ & \\
\hline \multicolumn{8}{|c|}{$\mathrm{pH}$} \\
\hline Coletas & datas & Local 1 & Local 2 & Local 3 & Local 4 & Local 5 & Médias \\
\hline $1^{\mathrm{a}}$ & 28.05 .07 & 5,80 & 5,68 & 6,12 & 6,24 & 6,02 & 5,97 \\
\hline $2^{a}$ & 04.07 .07 & 6,60 & 6,75 & 6,49 & 6,38 & 6,60 & 6,56 \\
\hline $3^{a}$ & 24.08 .07 & 7,14 & 7,04 & 7,10 & 6,45 & 7,25 & 7,00 \\
\hline $4^{a}$ & 05.10 .07 & 7,08 & 6,55 & 6,97 & 6,62 & 6,71 & 6,78 \\
\hline $5^{a}$ & 28.11 .07 & 7,0 & 7,03 & 8,8 & 7,7 & 7,30 & 7,57 \\
\hline $6^{\mathrm{a}}$ & 27.12 .07 & 6,30 & 6,30 & 6,30 & 6,60 & 6,20 & 6,34 \\
\hline $7^{a}$ & 22.01 .08 & 6,70 & 7,00 & 7,20 & 7,00 & 6,70 & 6,92 \\
\hline $8^{a}$ & 19.02 .08 & 7,50 & 6,60 & 6,40 & 6,40 & 6,40 & 6,66 \\
\hline $9^{\mathrm{a}}$ & 12.03 .08 & 6,70 & 6,10 & 6,40 & 6,20 & 6,40 & 6,36 \\
\hline $10^{\mathrm{a}}$ & 22.04 .08 & 6,90 & 7,40 & 6,90 & 6,70 & 7,20 & 7,02 \\
\hline
\end{tabular}


Tabela 1 (continuação)

\begin{tabular}{lccccccc}
\hline & \multicolumn{7}{c}{$\mathrm{pH}$} \\
\hline Coletas & datas & Local 1 & Local 2 & Local 3 & Local 4 & Local 5 & Médias \\
$11^{\mathrm{a}}$ & 12.05 .08 & 6,51 & 6,30 & 6,36 & 6,22 & 7,06 & 6,49 \\
$12^{\mathrm{a}}$ & 25.06 .08 & 6,50 & 6,10 & 6,30 & 6,10 & 6,60 & 6,32 \\
$13^{\mathrm{a}}$ & 23.07 .08 & 3,85 & 3,70 & 3,75 & 3,95 & 4,01 & 3,85 \\
$14^{\mathrm{a}}$ & 28.08 .08 & 6,62 & 6,16 & 6,31 & 6,06 & 7,39 & 6,51 \\
$15^{\mathrm{a}}$ & 24.09 .08 & 4,08 & 4,26 & 4,87 & 5,12 & 4,00 & 4,47 \\
$16^{\mathrm{a}}$ & 29.10 .08 & 6,17 & 5,85 & 5,68 & 5,48 & 7,65 & 6,17 \\
$17^{\mathrm{a}}$ & 18.11 .08 & 7,13 & 6,68 & 6,66 & 6,55 & 6,97 & 6,79 \\
$18^{\mathrm{a}}$ & 17.12 .08 & 6,88 & 6,67 & 6,98 & 3,61 & 8,31 & 6,49 \\
$19^{\mathrm{a}}$ & 27.01 .09 & 6,70 & 6,45 & 6,59 & 6,30 & 6,67 & 6,54 \\
$20^{\mathrm{a}}$ & 26.02 .09 & 6,00 & 5,82 & 6,06 & 6,04 & 6,78 & 6,14 \\
$21^{\mathrm{a}}$ & 24.03 .09 & 6,99 & 6,81 & 6,70 & 6,73 & 7,08 & 6,86 \\
$22^{\mathrm{a}}$ & 28.04 .09 & 6,48 & 6,87 & 6,73 & 6,45 & 7,08 & 6,72 \\
$23^{\mathrm{a}}$ & 26.05 .09 & 5,38 & 5,52 & 6,16 & 7,01 & 5,60 & 5,93 \\
$24^{\mathrm{a}}$ & 23.06 .09 & 6,81 & 6,56 & 6,61 & 6,31 & 7,19 & 6,69 \\
\hline
\end{tabular}

\begin{tabular}{lccccccc}
\hline & \multicolumn{7}{c}{ Condutividade } \\
\hline Coletas & datas & Local 1 & Local 2 & Local 3 & Local 4 & Local 5 & Médias \\
\hline $1^{\mathrm{a}}$ & 28.05 .07 & 0,022 & 0,017 & 0,028 & 0,033 & 0,023 & 0,025 \\
$2^{\mathrm{a}}$ & 04.07 .07 & 0,022 & 0,021 & 0,034 & 0,046 & 0,025 & 0,029 \\
$3^{\mathrm{a}}$ & 24.08 .07 & 0,022 & 0,020 & 0,033 & 0,046 & 0,029 & 0,030 \\
$4^{\mathrm{a}}$ & 05.10 .07 & 0,019 & 0,020 & 0,032 & 0,055 & 0,026 & 0,030 \\
$5^{\mathrm{a}}$ & 28.11 .07 & 0,024 & 0,026 & 0,034 & 0,071 & 0,028 & 0,037 \\
$6^{\mathrm{a}}$ & 27.12 .07 & 0,020 & 0,020 & 0,030 & 0,040 & 0,030 & 0,028 \\
$7^{\mathrm{a}}$ & 22.01 .08 & 0,020 & 0,020 & 0,030 & 0,050 & 0,030 & 0,030 \\
$8^{\mathrm{a}}$ & 19.02 .08 & 0,020 & 0,020 & 0,030 & 0,040 & 0,030 & 0,030 \\
$9^{\mathrm{a}}$ & 12.03 .08 & 0,020 & 0,020 & 0,030 & 0,050 & 0,020 & 0,028 \\
$10^{\mathrm{a}}$ & 22.04 .08 & 0,020 & 0,030 & 0,030 & 0,050 & 0,030 & 0,030 \\
$11^{\mathrm{a}}$ & 12.05 .08 & 0,020 & 0,020 & 0,020 & 0,040 & 0,020 & 0,020 \\
$12^{\mathrm{a}}$ & 25.06 .08 & 0,020 & 0,020 & 0,030 & 0,050 & 0,020 & 0,030 \\
$13^{\mathrm{a}}$ & 23.07 .08 & 0,017 & 0,016 & 0,026 & 0,046 & 0,040 & 0,029 \\
$14^{\mathrm{a}}$ & 28.08 .08 & 0,020 & 0,021 & 0,030 & 0,054 & 0,024 & 0,029 \\
$15^{\mathrm{a}}$ & 24.09 .08 & 0,020 & 0,021 & 0,032 & 0,053 & 0,047 & 0,035 \\
$16^{\mathrm{a}}$ & 29.10 .08 & 0,027 & 0,028 & 0,034 & 0,051 & 0,132 & 0,054 \\
$17^{\mathrm{a}}$ & 18.11 .08 & 0,011 & 0,028 & 0,034 & 0,053 & 0,029 & 0,031 \\
$18^{\mathrm{a}}$ & 17.12 .08 & 0,023 & 0,021 & 0,032 & 0,053 & 0,029 & 0,032 \\
$19^{\mathrm{a}}$ & 27.01 .09 & 0,025 & 0,023 & 0,029 & 0,051 & 0,027 & 0,031 \\
$20^{\mathrm{a}}$ & 26.02 .09 & 0,029 & 0,027 & 0,029 & 0,056 & 0,034 & 0,035 \\
$21^{\mathrm{a}}$ & 24.03 .09 & 0,023 & 0,022 & 0,027 & 0,048 & 0,027 & 0,029 \\
$22^{\mathrm{a}}$ & 28.04 .09 & 0,019 & 0,020 & 0,027 & 0,056 & 0,022 & 0,029 \\
$23^{\mathrm{a}}$ & 26.05 .09 & 0,019 & 0,019 & 0,029 & 0,052 & 0,025 & 0,029 \\
$24^{\mathrm{a}}$ & 23.06 .09 & 0,017 & 0,017 & 0,027 & 0,047 & 0,022 & 0,026 \\
\hline Médias & $0,021^{\mathrm{c}}$ & $0,021^{\mathrm{c}}$ & $0,029^{\mathrm{b}}$ & $0,049^{\mathrm{a}}$ & $0,032^{\mathrm{b}}$ & \\
\hline
\end{tabular}


Tabela 1 (continuação)

\begin{tabular}{cccccccc}
\hline \multicolumn{7}{c}{ Oxigênio } \\
\hline Coletas & Datas & Local 1 & Local 2 & Local 3 & Local 4 & Local 5 & Médias \\
\hline $1^{\mathrm{a}}$ & 28.05 .07 & 0,92 & 0,94 & 0,68 & 0,80 & 0,60 & 0,79 \\
$2^{\mathrm{a}}$ & 04.07 .07 & 5,12 & 6,52 & 5,72 & 4,40 & 7,43 & 5,84 \\
$3^{\mathrm{a}}$ & 24.08 .07 & 5,90 & 6,51 & 7,52 & 4,27 & 7,48 & 6,34 \\
$4^{\mathrm{a}}$ & 05.10 .07 & 6,47 & 5,74 & 7,07 & 4,01 & 6,08 & 5,87 \\
$5^{\mathrm{a}}$ & 28.11 .07 & 6,22 & 6,76 & 8,29 & 4,25 & 6,20 & 6,34 \\
$6^{\mathrm{a}}$ & 27.12 .07 & 3,20 & 5,50 & 6,60 & 5,10 & 7,10 & 5,50 \\
$7^{\mathrm{a}}$ & 22.01 .08 & 3,30 & 6,10 & 5,10 & 1,50 & 6,60 & 4,52 \\
$8^{\mathrm{a}}$ & 19.02 .08 & 3,10 & 6,10 & 5,90 & 1,30 & 7,50 & 4,78 \\
$9^{\mathrm{a}}$ & 12.03 .08 & 3,67 & 6,10 & 6,40 & 2,60 & 7,60 & 5,27 \\
$10^{\mathrm{a}}$ & 22.04 .08 & 4,70 & 5,20 & 7,50 & 3,00 & 6,70 & 5,42 \\
$11^{\mathrm{a}}$ & 12.05 .08 & 4,12 & 6,23 & 7,58 & 3,25 & 9,27 & 6,09 \\
$12^{\mathrm{a}}$ & 25.06 .08 & 5,60 & 7,00 & 8,00 & 3,00 & 8,50 & 6,42 \\
$13^{\mathrm{a}}$ & 23.07 .08 & 5,04 & 7,15 & 6,52 & 3,80 & 8,25 & 6,15 \\
$14^{\mathrm{a}}$ & 28.08 .08 & 4,55 & 6,89 & 5,70 & 2,42 & 8,21 & 5,55 \\
$15^{\mathrm{a}}$ & 24.09 .08 & 5,14 & 9,34 & 6,36 & 3,89 & 8,43 & 6,63 \\
$16^{\mathrm{a}}$ & 29.10 .08 & 3,50 & 5,14 & 6,84 & 3,04 & 7,00 & 5,10 \\
$17^{\mathrm{a}}$ & 18.11 .08 & 3,84 & 5,21 & 5,94 & 2,11 & 8,15 & 5,05 \\
$18^{\mathrm{a}}$ & 17.12 .08 & 3,66 & 6,23 & 6,80 & 3,61 & 8,31 & 5,72 \\
$19^{\mathrm{a}}$ & 27.01 .09 & 3,04 & 5,78 & 6,63 & 2,40 & 8,20 & 5,21 \\
$20^{\mathrm{a}}$ & 26.02 .09 & 3,00 & 6,95 & 5,40 & 1,85 & 7,78 & 4,99 \\
$21^{\mathrm{a}}$ & 24.03 .09 & 5,37 & 5,57 & 6,70 & 6,73 & 7,96 & 6,47 \\
$22^{\mathrm{a}}$ & 28.04 .09 & 4,27 & 5,54 & 8,27 & 2,78 & 7,78 & 5,73 \\
$23^{\mathrm{a}}$ & 26.05 .09 & 4,53 & 6,86 & 6,87 & 4,57 & 8,84 & 6,33 \\
$24^{\mathrm{a}}$ & 23.06 .09 & 5,04 & 7,30 & 7,31 & 4,58 & 9,48 & 6,74 \\
\hline Médias & & $4,30^{\mathrm{d}}$ & $6,11^{\mathrm{c}}$ & $6,48^{\mathrm{b}}$ & $3,30^{\mathrm{d}}$ & $7,48^{\mathrm{a}}$ & \\
\hline
\end{tabular}

Tabela 2. Táxons de fungos ingoldianos (a) e de fungos aquático-facultativos (b) isolados nas amostras de folhedo misto coletadas nos locais de 1 a 5, nos meses secos e frios, no período de 28.05.2007 a 23.06.2009, no Parque Municipal do Carmo, São Paulo, SP, Brasil. M: número de meses no qual o táxon foi registrado, O: número de registros da presença do táxon.

Table 2. Taxa of ingoldian fungi (a) and facultative aquatic fungi (b) isolated from mixed leaf litter collected in the sites 1 to 5, during the dry and cold months, in the period of 28.05.2007 to 23.06.2009, in the Parque Municipal do Carmo, São Paulo, São Paulo State, Brazil. M: number of months in which the taxon was recorded, O: number of records of the taxon.

(a) Fungos ingoldianos

\begin{tabular}{|c|c|c|c|c|c|c|c|c|c|c|c|}
\hline Números das coletas & $1^{\mathrm{a}}$ & $3^{\mathrm{a}}$ & $11^{\mathrm{a}}$ & $13^{\mathrm{a}}$ & $14^{\mathrm{a}}$ & $15^{\mathrm{a}}$ & $22^{\mathrm{a}}$ & $23^{\mathrm{a}}$ & $24^{\mathrm{a}}$ & $\mathrm{M}$ & $\mathrm{O}$ \\
\hline Meses das coletas & $5 / 07$ & $8 / 07$ & $5 / 08$ & $7 / 08$ & $8 / 08$ & $9 / 08$ & $4 / 09$ & $5 / 09$ & $6 / 09$ & & \\
\hline Anguillospora crassa Ingold & & & & & & 3,4 & & & 1 & 2 & 3 \\
\hline $\begin{array}{l}\text { Anguillospora longissimima (Sacc. et } \\
\text { Syd.) Ingold }\end{array}$ & & & & 5 & & & & & & 1 & 1 \\
\hline Campylospora chaetocladia Ranzoni & & & & 5 & & & & & & 1 & 1 \\
\hline Dendrospora sp. & & & 5 & & & & & & & 1 & 1 \\
\hline Lunulospora curvula Ingold & & & & 5 & & & & & & 1 & 1 \\
\hline
\end{tabular}


Tabela 2 (continuação)

\begin{tabular}{|c|c|c|c|c|c|c|c|c|c|c|c|}
\hline Números das coletas & $1^{\mathrm{a}}$ & $3^{\mathrm{a}}$ & $11^{\mathrm{a}}$ & $13^{\mathrm{a}}$ & $14^{\mathrm{a}}$ & $15^{\mathrm{a}}$ & $22^{\mathrm{a}}$ & $23^{\mathrm{a}}$ & $24^{\mathrm{a}}$ & $\mathrm{M}$ & $\mathrm{O}$ \\
\hline Meses das coletas & $5 / 07$ & $8 / 07$ & $5 / 08$ & $7 / 08$ & $8 / 08$ & $9 / 08$ & $4 / 09$ & $5 / 09$ & $6 / 09$ & & \\
\hline Margaritispora aquatica Ingold & & & & & $1,2,3,4,5$ & & 1 & & & 2 & 6 \\
\hline $\begin{array}{l}\text { Tripospermum camelopardus Ingold, } \\
\text { Dann et Mac Dougali }\end{array}$ & & & & & & & & 5 & & 1 & 1 \\
\hline $\begin{array}{l}\text { Tripospermum myrti (Lind.) S. J. } \\
\text { Hughes }\end{array}$ & 3 & & 3 & 1 & & & & & & 3 & 3 \\
\hline Tripospermum sp.1 & & & & & & & 2 & 1 & & 2 & 2 \\
\hline Triscelophorus acuminatus Nawawi & & 5 & & & & & & & & 1 & 1 \\
\hline Triscelophorus monosporus Ingold & & & & & 1 & 5 & & & 1 & 3 & 3 \\
\hline Varicosporium elodeae Kegel & & $1,3,4$ & & & & & & & & 1 & 3 \\
\hline $\mathrm{N}^{\circ}$. de táxons: 12 & 1 & 2 & 2 & 4 & 2 & 2 & 2 & 2 & 2 & & \\
\hline $\mathrm{N}^{\circ}$. ocorrências: 26 & 1 & 4 & 2 & 4 & 6 & 3 & 2 & 2 & 2 & & \\
\hline
\end{tabular}

(b) Fungos aquático-facultativos

\begin{tabular}{|c|c|c|c|c|c|c|c|c|c|c|c|c|}
\hline Números das coletas & $1^{\mathrm{a}}$ & $3^{a}$ & $11^{\mathrm{a}}$ & $12^{\mathrm{a}}$ & $13^{\mathrm{a}}$ & $14^{\mathrm{a}}$ & $15^{\mathrm{a}}$ & 22 & 23 & 24 & $\mathrm{M}$ & $\mathrm{O}$ \\
\hline Meses das coletas & $5 / 07$ & $8 / 07$ & $5 / 08$ & $6 / 08$ & $7 / 08$ & $8 / 08$ & $9 / 08$ & $4 / 09$ & $5 / 09$ & $6 / 09$ & & \\
\hline Alternaria alternata (Fr. Keissl.) & & & & 1 & 2 & 1 & & & & & 3 & 3 \\
\hline Beltrania rhombica Penz. & & & & & & & 1 & 2 & & & 2 & 2 \\
\hline Epiccocum nigrum Link. & 2 & & & & & & & & & & 1 & 1 \\
\hline Fusarium graminum Corda & & & & & & & & & & 5 & 1 & 1 \\
\hline $\begin{array}{l}\text { Fusarium semitectum Berk. \& } \\
\text { Ravenel }\end{array}$ & & $2,3,4$ & & & & & & & & & 1 & 3 \\
\hline Fusarium sp. & & & & & 5 & & & 2 & 5 & & 3 & 3 \\
\hline Pestalotiopsis sp. & & & & & 2 & & & & & 2 & 1 & 1 \\
\hline No de táxons: 07 & 1 & 1 & 0 & 1 & 3 & 1 & 1 & 2 & 1 & 2 & & \\
\hline No. ocorrências: 15 & 1 & 3 & 0 & 1 & 3 & 1 & 1 & 2 & 1 & 2 & & \\
\hline
\end{tabular}

Tabela 3. Táxons de fungos ingoldianos (a) e de fungos aquático-facultativos (b) isolados nas amostras de folhedo misto coletadas nos locais de 1 a 5, nos meses chuvosos e quentes, no período de 28.05.2007 a 23.06.2009, no Parque Municipal do Carmo, São Paulo, SP, Brasil. M: número de meses no qual o táxon foi registrado, O: número de registros da presença do táxon.

Table 3. Taxa of ingoldian fungi (a) and facultative aquatic fungi (b) isolated from mixed leaf litter collected in the sites 1 to 5, during the rainy and hot months, in the period of 28.05.2007 to 23.06.2009, in the Parque Municipal do Carmo, São Paulo, São Paulo State, Brazil. M: number of months in which the taxon was recorded, O: number of records of the taxon.

(a) Fungos ingoldianos

\begin{tabular}{|c|c|c|c|c|c|c|c|c|c|c|c|c|c|}
\hline Números das coletas & $5^{\mathrm{a}}$ & $6^{\mathrm{a}}$ & $7^{\mathrm{a}}$ & $8^{\mathrm{a}}$ & $10^{\mathrm{a}}$ & $16^{\mathrm{a}}$ & $17^{\mathrm{a}}$ & $18^{\mathrm{a}}$ & $19^{\mathrm{a}}$ & 20 & 21 & $\mathrm{M}$ & $\mathrm{O}$ \\
\hline Meses das coletas & $11 / 07$ & $12 / 07$ & $1 / 08$ & $2 / 08$ & $4 / 08$ & $10 / 08$ & $11 / 08$ & $12 / 08$ & $1 / 09$ & $2 / 09$ & $3 / 09$ & & \\
\hline Anguillospora crassa Ingold & 4 & 2 & & 1 & & 3,5 & & & & & & 4 & 5 \\
\hline $\begin{array}{l}\text { Anguillospora longissimima } \\
\text { (Sacc. et Syd.) Ingold }\end{array}$ & 4 & & & & & & 3 & 3 & & & & 3 & 3 \\
\hline $\begin{array}{l}\text { Camposporium pellucidum } \\
\text { (Grove) Hughes }\end{array}$ & 3 & & & & & & 3 & & & & & 2 & 2 \\
\hline
\end{tabular}


Tabela 3 (continuação)

\begin{tabular}{|c|c|c|c|c|c|c|c|c|c|c|c|c|c|}
\hline Números das coletas & $5^{\mathrm{a}}$ & $6^{\mathrm{a}}$ & $7^{\mathrm{a}}$ & $8^{\mathrm{a}}$ & $10^{\mathrm{a}}$ & $16^{\mathrm{a}}$ & $17^{\mathrm{a}}$ & $18^{\mathrm{a}}$ & $19^{\mathrm{a}}$ & 20 & 21 & $\mathrm{M}$ & $\mathrm{O}$ \\
\hline Meses das coletas & $11 / 07$ & $12 / 07$ & $1 / 08$ & $2 / 08$ & $4 / 08$ & $10 / 08$ & $11 / 08$ & $12 / 08$ & $1 / 09$ & $2 / 09$ & $3 / 09$ & & \\
\hline Dendrospora erecta Ingold & & & & & & 5 & & & & & & 1 & 1 \\
\hline $\begin{array}{l}\text { Flabellospora crassa } \\
\text { Alasoadura }\end{array}$ & & & & 1 & & & & & & & & 1 & 1 \\
\hline $\begin{array}{l}\text { Lemonniera aquatica De } \\
\text { Wild. }\end{array}$ & & & & & & & & & 5 & & & 1 & 1 \\
\hline Lunulospora curvula Ingold & 4 & & & & 5 & 5 & & & & & & 3 & 3 \\
\hline $\begin{array}{l}\text { Margaritispora aquatica } \\
\text { Ingold }\end{array}$ & & 3 & & 1 & & & 2 & & & & & 3 & 3 \\
\hline Naiadella sp. & & & & & & 4 & & & & & & 1 & 1 \\
\hline $\begin{array}{l}\text { Tetracladium maxilliforme } \\
\text { (Rostr.) Ingold }\end{array}$ & & & & & & & & & & 1,2 & & 1 & 2 \\
\hline $\begin{array}{l}\text { Tetracladium setigerum } \\
\text { (Grove) Ingold }\end{array}$ & & & & & $1,2,3$ & & & & & & & 1 & 3 \\
\hline Tetraploa sp. & 4 & & & & & & & & & & & 1 & 1 \\
\hline $\begin{array}{l}\text { Tripospermum myrti (Lind.) } \\
\text { S.J. Hughes }\end{array}$ & 2 & & & & & & & & & & & 1 & 1 \\
\hline Tripospermum sp.1 & & & 1 & & & & & & & & & 1 & 1 \\
\hline Tripospermum sp.2 & & & & & & & & & 5 & & & 1 & 1 \\
\hline $\begin{array}{l}\text { Triscelophorus acuminatus } \\
\text { Nawawi }\end{array}$ & & & & & & & & & 5 & & & 1 & 1 \\
\hline $\begin{array}{l}\text { Triscelophorus monosporus } \\
\text { Ingold }\end{array}$ & & & 2 & & & $2,4,5$ & 3 & 5 & & & & 4 & 6 \\
\hline Triscelophorus sp. & & & & & & & & 3 & & & & 1 & 1 \\
\hline $\begin{array}{l}\text { Varicosporium elodeae } \\
\text { Kegel }\end{array}$ & & & & & & & & & & 3 & & 1 & 1 \\
\hline No. de táxons: 19 & 6 & 2 & 2 & 3 & 2 & 5 & 4 & 3 & 3 & 2 & 0 & & \\
\hline No. ocorrências: 38 & 6 & 2 & 2 & 3 & 4 & 8 & 4 & 3 & 3 & 3 & 0 & & \\
\hline
\end{tabular}

(b) Fungos aquático-facultativos

\begin{tabular}{|c|c|c|c|c|c|c|c|c|c|c|c|c|c|}
\hline Números das coletas & $5^{\mathrm{a}}$ & $6^{\mathrm{a}}$ & $7^{\mathrm{a}}$ & $8^{\mathrm{a}}$ & $10^{\mathrm{a}}$ & $16^{\mathrm{a}}$ & $17^{\mathrm{a}}$ & $18^{\mathrm{a}}$ & $19^{\mathrm{a}}$ & 20 & 21 & $\mathrm{M}$ & $\mathrm{O}$ \\
\hline Meses das coletas & $11 / 07$ & $12 / 07$ & $1 / 08$ & $2 / 08$ & $4 / 08$ & $10 / 08$ & $11 / 08$ & $12 / 08$ & $1 / 09$ & $2 / 09$ & $3 / 09$ & & \\
\hline Beltrania sp. & & & & & & 5 & & & & & & 1 & 1 \\
\hline $\begin{array}{l}\text { Curvularia lunata (Wakker) } \\
\text { Boedijn }\end{array}$ & & & & & & & & & & 1,2 & & 2 & 2 \\
\hline Curvularia sp. & 3 & & & & & & & & & & & 1 & 1 \\
\hline $\begin{array}{l}\text { Cylindrocladium scoparium } \\
\text { Morgan }\end{array}$ & & & & & & & & & & 4,5 & $2,3,4,5$ & 2 & 6 \\
\hline Dictyochaeta sp. & & & 4 & & & & & & & & & 1 & 1 \\
\hline Endophragmiella sp. & & & & & & 3 & & & 2 & & & 2 & 2 \\
\hline Pestalotiopsis sp. & & 4,5 & & & & & & & & & & 1 & 2 \\
\hline $\mathrm{N}^{\circ}$ de táxons: 07 & 1 & 1 & 1 & 0 & 0 & 2 & 0 & 0 & 1 & 2 & 1 & & \\
\hline No. ocorrências: 15 & 1 & 2 & 1 & 0 & 0 & 2 & 0 & 0 & 1 & 4 & 4 & & \\
\hline
\end{tabular}


Tabela 4. Táxons de fungos ingoldianos (a) e de fungos aquático-facultativos (b) isolados nas amostras de folhedo misto coletadas nos locais de 1 a 5, nos meses secos e quentes, chuvosos e frios, no período de 28.05.2007 a 23.06.2009 no Parque Municipal do Carmo, São Paulo, SP, Brasil. M: número de meses no qual o táxon foi registrado, O: número de registros da presença do táxon.

Table 4. Taxa of ingoldian fungi (a) and facultative aquatic fungi (b) isolated from mixed leaf litter collected in the sites 1 to 5, during the dry and hot, rainy and cold months, in the period of 28.05.2007 to 23.06.2009, in the Parque Municipal do Carmo, São Paulo, São Paulo State, Brazil. M: number of months in which the taxon was recorded, O: number of records of the taxon.

(a) Fungos ingoldianos - meses secos e quentes

\begin{tabular}{lcccc}
\hline Números das coletas & $4^{\mathrm{a}}$ & $9^{\mathrm{a}}$ & $\mathrm{M}$ & $\mathrm{O}$ \\
\hline Meses das coletas & $10 / 07$ & $3 / 08$ & & 1 \\
\hline $\begin{array}{l}\text { Dendrospora sp. } \\
\text { Margaritispora aquatica Ingold }\end{array}$ & 2 & 1 & 1 \\
Tripospermum myrti (Lind.) S. J. & $1,2,3,5$ & 4 & 1 & 4 \\
Hughes & & 1,5 & 1 & 2 \\
Triscelophorus acuminatus Nawawi & & 2 & 1 & 1 \\
Triscelophorus monosporus Ingold & 5 & & 1 & 1 \\
Varicosporium elodeae Kegel & 2 & 4 & & \\
\hline $\mathrm{N}^{\circ}$. de táxons: 06 & 5 & 5 & & \\
\hline $\mathrm{N}^{\circ}$. ocorrências: 10 & & & & \\
\hline
\end{tabular}

(b) Fungos aquático-facultativos - meses secos e quentes

\begin{tabular}{lccc}
\hline Número da coleta & $9^{\mathrm{a}}$ & $\mathrm{M}$ & $\mathrm{O}$ \\
\hline Mes da coleta & $3 / 08$ & & 1 \\
Curvularia lunata (Wakker) Boedijn & 1 & 1 & 1 \\
Fusarium graminum Corda & 1 & 1 & \\
\hline $\mathrm{N}^{\circ}$ de táxons: 02 & & & \\
\hline $\mathrm{N}^{\circ}$. ocorrências: 02 & & \\
\hline
\end{tabular}

(a) Fungos ingoldianos - meses chuvosos e frios

\begin{tabular}{lccc}
\hline Número da coleta & $2^{\mathrm{a}}$ & $\mathrm{N}$ & $\mathrm{O}$ \\
\hline Mês & $7 / 07$ & & \\
Tripospermum myrti (Lind.) S. J. Hughes & 3 & 1 & 1 \\
\hline
\end{tabular}

(b) Fungos aquático-facultativos - meses chuvosos e frios

\begin{tabular}{|c|c|c|c|}
\hline Número da coleta & $2^{\mathrm{a}}$ & $\mathrm{M}$ & $\mathrm{O}$ \\
\hline Mês & $7 / 07$ & & \\
\hline Epiccocum nigrum Link. & 2 & 1 & 1 \\
\hline No de táxons: 01 & 1 & & \\
\hline No ocorrências: 01 & 1 & & \\
\hline
\end{tabular}


Tabela 5. Números totais de táxons $(\mathrm{T})$ e de ocorrências $(\mathrm{O})$ dos fungos ingoldianos e dos fungos aquático-facultativos obtidos nas amostras de folhedo misto coletadas nos locais de 1 a 5 , nos meses agrupados de acordo com as condições climáticas, no período de 28.05.2007 a 23.06.2009, no Parque Municipal do Carmo, São Paulo, SP, Brasil.

Table 5. Total number of taxa $(\mathrm{T})$ and occurrences $(\mathrm{O})$ of ingoldian fungi and facultative aquatic fungi obtained from mixed leaf litter samples collected in the sites 1 to 5 , in the collection months clustered according to climatic conditions, during the period of 28.05.2007 and 23.06.2009, in the Parque Municipal do Carmo, São Paulo, São Paulo State, Brazil.

Fungos ingoldianos

\begin{tabular}{lllllllll}
\hline Clima & \multicolumn{2}{c}{ Seco e frio } & \multicolumn{2}{c}{ Chuvoso e quente } & \multicolumn{2}{c}{ Seco e quente } & \multicolumn{2}{c}{ Chuvoso e frio } \\
\hline Números totais & $\mathrm{T}$ & $\mathrm{O}$ & $\mathrm{T}$ & $\mathrm{O}$ & $\mathrm{T}$ & $\mathrm{O}$ & $\mathrm{T}$ & $\mathrm{O}$ \\
\hline Locais & & & & & & & & \\
1 & 6 & 8 & 6 & 6 & 2 & 2 & - & \\
2 & 2 & 2 & 6 & 7 & 3 & 3 & - & 1 \\
3 & 4 & 5 & 8 & 10 & 1 & 1 & 1 & \\
4 & 3 & 3 & 6 & 6 & 1 & 1 & - & - \\
5 & 8 & 8 & 7 & 9 & 3 & 3 & - \\
\hline
\end{tabular}

Fungos aquático-facultativos

\begin{tabular}{|c|c|c|c|c|c|c|c|c|}
\hline \multirow{2}{*}{$\begin{array}{l}\text { Clima } \\
\text { Números totais }\end{array}$} & \multicolumn{2}{|c|}{ Seco e frio } & \multicolumn{2}{|c|}{ Chuvoso e quente } & \multicolumn{2}{|c|}{ Seco e quente } & \multicolumn{2}{|c|}{ Chuvoso e frio } \\
\hline & $\mathrm{T}$ & $\mathrm{O}$ & $\mathrm{T}$ & $\mathrm{O}$ & $\mathrm{T}$ & $\mathrm{O}$ & $\mathrm{T}$ & $\mathrm{O}$ \\
\hline \multicolumn{9}{|l|}{ Locais } \\
\hline 1 & 2 & 3 & 1 & 1 & 2 & 2 & & \\
\hline 2 & 6 & 7 & 3 & 3 & & & 1 & 1 \\
\hline 3 & 1 & 1 & 3 & 3 & & & & \\
\hline 4 & 1 & 1 & 3 & 4 & & & & \\
\hline 5 & 1 & 3 & 3 & 4 & & & & \\
\hline
\end{tabular}

Fungos ingoldianos + fungos aquático-facultativos

\begin{tabular}{lcccccccc}
\hline Clima & \multicolumn{2}{c}{ Seco e frio } & \multicolumn{2}{c}{ Chuvoso e quente } & \multicolumn{2}{c}{ Seco e quente } & \multicolumn{2}{c}{ Chuvoso e frio } \\
\hline Números totais & $\mathrm{T}$ & $\mathrm{O}$ & $\mathrm{T}$ & $\mathrm{O}$ & $\mathrm{T}$ & $\mathrm{O}$ & $\mathrm{T}$ & $\mathrm{O}$ \\
\hline Locais & & & & & & & & \\
1 & 8 & 11 & 7 & 7 & 4 & 4 & 0 & 0 \\
2 & 8 & 9 & 9 & 10 & 3 & 3 & 1 & 1 \\
3 & 5 & 6 & 11 & 13 & 1 & 1 & 1 & 1 \\
4 & 4 & 4 & 9 & 10 & 1 & 1 & 0 & 0 \\
5 & 10 & 11 & 10 & 13 & 3 & 3 & 0 & 0 \\
\hline
\end{tabular}

Fungos ingoldianos + aquático-facultativos (desconsiderando as épocas climáticas)

\begin{tabular}{llllllc}
\hline Locais: & \multicolumn{2}{c}{ Táxons totais } & \multicolumn{2}{c}{ Fungos ingoldianos } & \multicolumn{2}{c}{ Fungos aquático-facultativos } \\
\hline Registros & $\mathrm{T}$ & $\mathrm{O}$ & $\mathrm{T}$ & $\mathrm{O}$ & $\mathrm{T}$ & $\mathrm{O}$ \\
\hline 1 & 14 & 22 & 10 & 16 & 4 & 6 \\
2 & 17 & 23 & 8 & 12 & 9 & 11 \\
3 & 13 & 21 & 9 & 17 & 4 & 4 \\
4 & 12 & 15 & 8 & 10 & 4 & 5 \\
5 & 19 & 26 & 14 & 20 & 5 & 6 \\
\hline
\end{tabular}


presentes em pelo menos três meses durante o período estudado, destacaram-se Tripospermum myrti (Lind.) S.J. Hughes e Triscelophorus monosporus Ingold. Quanto aos fungos aquático-facultativos, Alternaria alternata (Fr. Keissl.) e Fusarium sp. ocorrem em três meses secos e frios, entre os quais em julho de 2008 foi obtido o maior número de táxons.

Nos meses chuvosos e quentes (tabela 3), o número de táxons, correspondente a 19 (38 ocorrências) apresentou-se maior do que nos meses secos e frios (tabela 2). Anguillospora crassa Ingold, Triscelophorus monosporus, Lunuslopora curvula Ingold e Margaritispora aquática Ingold e Anguillospora longíssima (Sacc. et Syd.) Ingold foram os fungos ingoldianos mais frequentes e os meses de novembro de 2007, outubro e novembro de 2008, os com maiores números de táxons destes fungos. Entre os fungos aquático-facultativos, destacou-se Cylindrocladium scoparium Morgan, pelo maior número de ocorrências.

Nos meses secos e quentes (tabela 4), que foram outubro de 2007 e março de 2008, ocorreram seis fungos ingoldianos, entre os quais destacou-se Tripospermum myrti (Lind.) S. J. Hughes pelo maior número de ocorrências. Em março de 2008 ocorreram quatro táxons de fungos ingoldianos e dois fungos aquático-facultativos, a saber: Curvularia lunata (Wakker) Boedijn e Fusarium graminum Corda. Julho de 2007 foi considerado chuvoso e frio no qual ocorreu somente Tripospermum myrti (Lind.) S.J. Hughes e Epicoccum nigrum Link.

Em 22 táxons de fungos ingoldianos, 9 ocorreram tanto em condições de clima seco e frio (tabela 2), quanto no chuvoso e quente (tabela 3 ). Entre esses, seis táxons, Dendrospora sp., Margaristispora aquática, Tripospermum myrtii, Triscelophorus acuminatus, Triscelophorus monosporus e Varicosporium elodae ocorreram também em condições de clima seco e quente (tabela 4). T. myrtii também ocorreu em condições de clima chuvoso e frio (tabela 4). Somando-se os dados das coletas dos meses de clima seco e frio (tabela 2), verifica-se a obtenção de 12 táxons, entre os quais Campylospora chaetocladia e Tripospermum camelopardus ocorreram somente nestas condições. Por outro lado, nos meses chuvosos e quentes (tabela 3), o número de táxons apresentou-se maior, correspondente a 19, com 10 táxons que ocorreram exclusivamente nestas condições climáticas.

Com relação aos fungos aquático-facultativos, nos meses de clima seco e frio (tabela 2) e nos meses de clima chuvoso e quente (tabela 3 ) as micotas foram constituídas pelo mesmo número de táxons, sete, porém com composição diferente, tendo somente a ocorrência de Pestalotiopsis sp. em comum.

Curvularia lunata e Fusarium graminum foram registradas em mês de clima seco e quente (tabela 4), sendo que o primeiro táxon ocorreu também no clima chuvoso e quente (tabela 3 ) e o segundo no clima seco e frio (tabela 4). Epicoccum nigrum foi registrado em mês seco e frio (tabela 2) e também em mês chuvoso e frio (tabela 4).

Levando em conta as épocas climáticas (tabela 5), verifica-se no local 5, os números de táxons e de ocorrências são semelhantes na comparação dos meses secos e frios com os chuvosos e quentes, diminuindo sensivelmente nos meses secos e quentes. Entretanto nos locais 3 (lago mais preservado) e 4 (local assoreado), o número de táxons totais e de ocorrências praticamente dobrou nos meses chuvosos e quentes.

Analisando os locais de coleta (tabela 5) sem considerar as épocas climáticas, verifica-se que o local 5, o riacho, apresentou o maior número total de táxons e de ocorrências totais e especificamente de fungos ingoldianos. Dos fungos aquático-facultativos, o número de táxons e de ocorrências apresentou-se maior no local 2, que é um lago. O menor número de táxons e de ocorrências totais ocorreu no local 4, no lago assoreado.

Cumprindo o objetivo de auxiliar a compreensão da influência das épocas climáticas e dos locais de coleta sobre a diversidade dos fungos, a figura 1 apresenta a distribuição espacial dos locais de coleta nas épocas chuvosas e quentes e épocas secas e frias, em função da similaridade dos táxons totais. Assim, a micota do local 1 difere menos entre as épocas climáticas do que o local 2, no qual as micotas (2cq e $2 \mathrm{sf}$ ) encontram-se em quadrantes diferentes. Também são pouco semelhantes as micotas nas épocas secas e frias com as nas épocas chuvosas e quentes no local 3 e 5 , enquanto as micotas do local 4 diferem consideravelmente entre as épocas climáticas.

O teste de Spearman revelou correlação positiva entre o número de táxons de fungos ingoldianos e os valores da temperatura da água (teste de correlação de Spearman, $p=0,043$ ), e positiva para a condutividade (teste de correlação de Spearman, $\mathrm{p}=0,024$ ).

\section{Discussão}

De modo geral, as variáveis abióticas medidas nas águas do Parque do Carmo acompanharam as variações climáticas do período estudado e das 


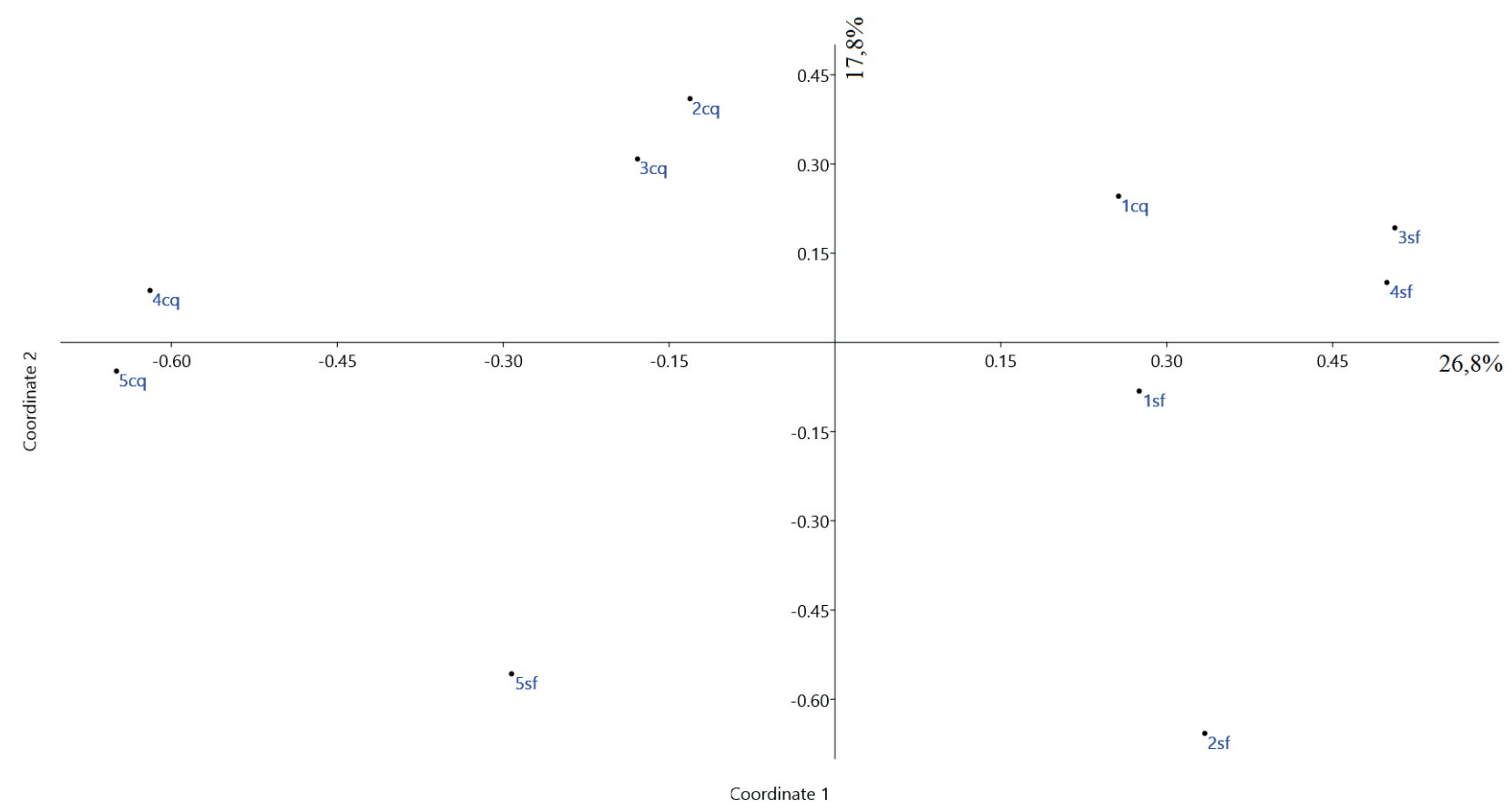

Figura 1. Distribuição espacial dos locais de coleta, Parque Municipal do Carmo, São Paulo, SP, Brasil, nas épocas chuvosas e quentes e épocas secas e frias, em função da similaridade dos táxons totais.

Figure 1. Spatial distribution of the collection sites, Parque Municipal do Carmo, São Paulo, São Paulo State, Brazil, in the rainy and hot seasons, and in the dry and cold seasons, due to the similarity of the total taxa.

características peculiares de cada local de coleta. Os valores individuais e médios da temperatura medida na água apresentaram a tendência de serem maiores no local 3, que se situa na parte mais ensolarada do lago central. Situação contrária se mostrou no local 5 , que é um dos riachos afluentes do lago central, localizado sob sombra e com fluxo de água contínuo.

A condutividade apresentou a tendência de ser maior no local 4, provavelmente por causa de grande quantidade de material em suspensão e assoreamento. Em contrapartida, os menores valores de condutividade foram registrados nos locais 1 e 2 , cujas águas são as mais próximas às entradas de água que formam o lago central. Os valores médios da condutividade elétrica das águas do Parque do Carmo apresentam-se bem menores do que os determinados no Parque da Aclimação, situados entre 0,120 e $0,251 \mu \mathrm{Scm}^{-3}$ (Schoenlein-Crusius et al. 2015), mas são compatíveis com os valores médios encontrados no Córrego Pirarungaua, ao redor de $0,046 \mu \mathrm{Scm}^{-3}$ (Schoenlein-Crusius et. al. 2016).

Provavelmente em decorrência da turbulência e limpidez do riacho, as medições do teor de oxigênio dissolvido na água tenderam a serem maiores no local 5. Com relação às condições de $\mathrm{pH}$ e oxigênio dissolvido exigidas pela Resolução CONAMA n ${ }^{\circ} 357$ de 15.03.2005 para águas da classe 4, foram registrados valores de $\mathrm{pH}$ abaixo de 6,0 somente em maio, julho de 2007 e em setembro, outubro de 2008. Com relação ao oxigênio dissolvido os teores se mostraram muito baixos, isto é, menores que $2,0 \mathrm{mgO}_{2} \cdot \mathrm{L}^{-1}$ somente em maio de 2007, portanto dentro da normalidade para a classe 4.

Os táxons de fungos ingoldianos e dos aquáticofacultativos aqui citados já foram reportados em estudos realizados no Brasil (Schoenlein-Crusius \& Malosso 2007). Táxons como Triscelophorus monosporus, Lunulospora curvula e Anguillospora crassa foram citados em diversos levantamentos destes fungos na Mata Atlântica, Cerrado e outros biomas (Fiuza et al. 2017). Margaritispora aquatica também foi muito citada em folhedo em decomposição em diversas águas urbanas (Schoenlein-Crusius \& Malosso 2007).

Incluindo os dados referentes à riqueza dos fungos no presente artigo, os outros parques municipais (Moreira \& Schoenlein-Crusius 2012; SchoenleinCrusius et al. 2014; Schoenlein-Crusius et al. 2015) apresentaram os seguintes números totais de táxons: Parque do Carmo (35), Parque Alfredo Volpi (34), 
Parque do Ibirapuera (27) e Parque da Aclimação (26). Especificamente com relação aos fungos ingoldianos verificou-se: Parque do Carmo (23 táxons), Parque Alfredo Volpi (18), Parque da Aclimação (16) e do Ibirapuera (15 táxons). Com relação aos fungos facultativos, verificou-se a seguinte sequência: Parque Alfredo Volpi (16 táxons), Parque do Carmo (12 táxons), Parque do Ibirapuera (12 táxons) e Parque da Aclimação (10 táxons). Verifica-se, portanto, que as águas do Parque do Carmo oferecem bom suporte para uma micota aquática rica e diversificada com relação aos outros parques municipais acima citados.

Tendo em vista que na literatura a presença dos fungos ingoldianos sempre foi associada a águas lóticas, moderadamente turbulentas, limpas e frias (Ingold 1975, Bärlocher 1992), o fato de ter sido observado maior número de táxons no riacho faz sentido.

Com exceção do local 1, via de regra, o número de táxons e de ocorrências de fungos ingoldianos se elevaram nos meses chuvosos e quentes, alterando-se pouco nas demais épocas climáticas (tabelas 2, 3 e 4). Com relação aos fungos aquático-facultativos, nos locais 3, 4 e 5 o número de táxons aumentou nos meses chuvosos e quentes em relação aos demais, enquanto no local 1 e especialmente no local 2, ocorreu o contrário. Portanto verifica-se que o tipo de época climática exerceu maior influência sobre a diversidade dos fungos do que a variabilidade dos locais de coleta. Estes resultados concordam com os reportados para outros parques, pois tanto no Parque do Ibirapuera (Schoenlein-Crusius et. al. 2014) quanto no Parque da Aclimação (Schoenlein-Crusius et. al. 2015) a micota apresentou a tendência de ser mais rica nos meses chuvosos e quentes do que nos secos e frios, o que justifica a correlação positiva entre o número de táxons de fungos ingoldianos e os valores da temperatura da água, e positiva para a condutividade.

Nos países de clima temperado, as épocas de maior disponibilidade de matéria orgânica alóctone nos ambientes lóticos são o outono e a primavera, nos quais a temperatura e a condutividade das águas são menores. Como a ocorrência dos fungos ingoldianos tem sido muito associada ao montante disponível de folhas senescentes nos corpos d'água (Bärlocher $\&$ Sridhar 2014), existe a possibilidade do maior carreamento das mesmas para dentro dos riachos e lagos nas épocas mais chuvosas e quentes justificar as correlações acima mencionadas e que se têm repetido em diversos parques urbanos.
A influência da temperatura e da condutividade sobre os fungos que vivem nos ambientes aquáticos é complexa porque depende de diversos fatores como o tipo de bioma, as características intrínsecas do corpo d'água, o nível de eutrofização e da espécie de fungo. Corpos d'água oligotróficos geralmente restringem a diversidade fúngica (Suberkropp \& Chauvet 1995), níveis moderados de fósforo e de nitrogênio estimulam o aumento da riqueza da micota (Woodward et al. 2012) e o excesso de eutrofização, aliado à presença de poluentes como metais pesados e outros, acarretam a diminuição da diversidade das espécies (Pascoal \& Cássio 2008).

Com relação à temperatura, a intensidade de sua influência depende da espécie fúngica (Ferreira et al. 2012). Espécies como Lunulospora curvula produzem o número máximo de conídios em temperaturas elevadas, ao redor de $25{ }^{\circ} \mathrm{C}$, sendo conhecidas como espécies de águas mais quentes, enquanto Flagellospora curvula, que produz maior quantidade de conídios em temperaturas ao redor de $15^{\circ} \mathrm{C}$, faz parte das espécies típicas de águas mais frias. Assim, as diferentes temperaturas ótimas de cada espécie individual determina, em conjunto, a sazonalidade da abundância de conídios em cada riacho (Gessner et al. 1993, Nikolcheva \& Bärlocher 2005).

A correlação entre a condutividade elétrica e a riqueza dos fungos nos ambientes aquáticos do Parque do Carmo é mais difícil de ser compreendida, em parte porque se desconhece quais fatores contribuíram para que os valores da variável fossem baixos com relação à outros parques urbanos em São Paulo (SchoenleinCrusius et al. 2013, 2015), apesar de compatível com os valores registrados nas águas do Córrego Pirarungaua, em fase de revitalização (SchoenleinCrusius et al. 2016).

Apesar da condutividade não expressar o nível de eutrofização das águas, ou seja, águas com condutividade reduzida não são necessariamente livres de poluição, valores baixos significam que há poucos elementos que conduzem corrente elétrica. Como os fungos que vivem no ambiente aquático conseguem absorver elementos presentes na coluna d'água (Suberkropp 1995), a maior presença destes elementos talvez possa estimular a diversidade dos fungos, justificando a correlação positiva entre fungos ingoldianos e a condutividade elétrica como verificado no presente estudo. A elevação da condutividade elétrica das águas do Parque do Carmo ocorreu nas épocas chuvosas e quentes, quando o número de táxons de fungos apresentou-se maior, enquanto o 
contrário ocorreu nas épocas mais frias e secas. Zang et al. (2016) encontraram de maneira semelhante correlações positivas entre a condutividade elétrica e da temperatura da água com a diversidade da micota aquática, atribuindo este resultado ao total de sólidos orgânicos e inorgânicos presentes nas águas estudadas no ártico.

Diante das mudanças climáticas globais e maiores níveis de gás carbônico na atmosfera, espera-se que a temperatura global aumente e flutue mais, atuando sobre a atividade dos fungos e também dos invertebrados com os quais a micota aquática se relaciona significativamente durante a decomposição de substratos foliares, aumentando a velocidade desse processo e atuando sobre a diversidade e composição da micota (Bärlocher et al. 2008, Bärlocher \& Sridhar 2014). Os resultados encontrados no Parque do Carmo auxiliam a compreender estes mecanismos e estimulam a continuidade dos estudos de fungos aquáticos em águas urbanas.

\section{Agradecimentos:}

Os autores agradecem ao Departamento de Áreas Verdes da Prefeitura do Município de São Paulo, pela autorização de coleta e ao $\mathrm{CNPq}$, pela bolsa de produtividade para a primeira autora (processo 306923/2006-8).

\section{Literatura citada}

Bärlocher, F. \& Sridhar, K.R. 2014. Association of animals and fungi in leaf decomposition. In: G. Jones, K. Hyde \& K.L. Pang (eds.). Freshwater Fungi and Fungus-like Organisms, De Gruyter Pub., Hong Kong, pp. 1-19.

Bärlocher, F. 1992. Research on aquatic hyphomycetes: historical background and overview. In: F. Bärlocher (ed.). The Ecology of Aquatic Hyphomycetes. Springer Verlag, Berlin, pp. 1-15.

Bärlocher, F., Seena, S.,Wilson, K.P. \& Williams, D.D. 2008. Raised water temperature lowers diversity of hyporheic aquatic hyphomycetes. Freshwater Biology 53: 368-379.

Baschien, C., Marvanová, L. \& Szewzyk, U. 2006. Phylogeny of selected aquatic hyphomycetes based on morphological and molecular data. Nova Hedwigia 83: 311-352.

Borg, I \& Groenen, P. 2005. Modern Multidimensional Scaling: theory and applications. 2 ed. Springer-Verlag, New York.

Burgos, E.J. \& Castillo, P.H. 1986. Hyphomycetes acuaticos como indicadores de contaminacion. Biota 2: $1-10$.
Centro de Pesquisas de História Natural. 1988. Conheça o verde. Supervisão de Goro Hashimoto. CPHN, São Paulo, fascículos 1-15.

Ferreira, V., Gonçalves, A.L. \& Canhoto, C. 2012. Aquatic hyphomycete strains from metal-contaminated and reference streams might respond differently to future increases in temperature. Mycologia 104: 613-622.

Fiuza, P. O., Cantillo-Pérez, T., Gulis, V. \& Gusmão, L.F.P. 2017. Ingoldian fungi of Brazil: some new records and a review including a checklist and a key. Phytotaxa 306: 171-200.

Gessner, M.O., Bauchrowitz, M.A. \& Escautier, M. 1991. Extraction and quantification of ergosterol as a measure of fungal biomass in leaf litter. Microbial Ecology 22: 285-291.

Gessner, M.O., Thomas, M., Jean-Louis, A.M. \& Chauvet, E. 1993. Stable successional patterns of aquatic hyphomycetes on leaves decaying in a summer cool stream. Mycological Research 97: 163-172.

Goh, T.K. \& Hyde, K.D. 1996. Biodiversity of freshwater fungi. Journal of Industrial Microbiology 17: 328-345.

Ingold, C.T. 1975. An Illustrated Guide to Aquatic and Water-borne Hyphomycetes (Fungi Imperfecti) with notes on their Biology. Freshwater Biological Association n. 30, Ambleside, U.K.

Marvanová, L. 1997. Freshwater Hyphomycetes: a survey with remarks on tropical taxa. In: K.K. Janardhanan, C. Rajendran, K. Natarajan \& D.L. Hawksworth (eds.). Tropical Mycology. Science Publishers Inc.

Moreira, C.G. \& Schoenlein-Crusius, I.H. 2012. Nova espécie e novos registros para o Brasil de Hyphomycetes em folhedo submerso coletados no Parque Municipal Alfredo Volpi, São Paulo, SP, Brasil. Hoehnea 39: 521-527.

Nikolcheva, L.G. \& Bärlocher, F. 2005. Seasonal and substrate preferences of fungi colonizing leaves in streams: traditional versus molecular evidence. Environmental Microbiology 7: 270-280.

Pascoal, C. \& Cássio, F. 2008. Linking fungal diversity to the functioning of freshwater ecosystems. Fungal Diversity 20: 1-19.

Santos-Flores, C.J. \& Betancourt-López, C. 1999. Aquatic and Water-borne Hyphomycetes (Deiteromycotina) in streams of Puerto Rico (including records from other Neotropical locations). Caribbean Journal of Science 2 , special publication.

Schoenlein-Crusius, I. H. \& Malosso, E. 2007. Diversity of Aquatic Hyphomycetes in the tropics. In: B.N. Ganguli \& S.K. Deshmukh (eds.). Fungi: multifaceted microbes. Anamaya Publishers, New Delhi, pp. 61-81.

Schoenlein-Crusius, I.H., Moreira, C.G., Takahashi, J.P. \& Gomes, E.P.C. 2014. Riqueza dos fungos ingoldianos e aquático-facultativos no Parque Municipal do Ibirapuera, São Paulo, SP, Brasil. Hoehnea 41:61-76. 
Schoenlein-Crusius, I.H., Moreira, C.G. \& Gomes, E.PC. 2015. Riqueza dos fungos ingoldianos e dos fungos aquáticos facultativos do Parque Municipal da Aclimação, São Paulo, SP, Brasil. Hoehnea 42: 239-251.

Schoenlein-Crusius, I.H., Diniz, B.F., Costa, R.T., Sabino, A.P.R., Moro, L.B., Boro, M., Ishida, C. M., Jesus, A.L. \& Pires-Zottarelli, C.L.A. 2016. Diversity of conidial fungi and some abiotic variables of the water after reopening of the Pirarungaua stream in the Jardim Botânico, São Paulo, São Paulo State, Brazil. Hoehnea 43: 57-75.

Suberkropp, K. \& Chauvet, E. 1995. Regulation of leaf breakdown by fungi in streams: influences of water chemistry. Ecology 76: 1433-1445.
Suberkropp, K. 1995. The influence of nutrients on fungal growth, productivity, and sporulation during leaf breakdown in streams. Canadian Journal of Botany 73: 1361-1369.

Woodward, G., Gessner, M.O., Giller, P.S., Gulis, V., Hladyz, S. \& Lecerf, S. 2012. Continental-scale effects of nutrient pollution on stream ecosystem functioning. Science 336: 1438-1440.

Zhang,T., Wang, N.F., Zhang, Y.Q., Liu, H.Y \& Yu, L.Y. 2016. Diversity and Distribution of Aquatic Fungal Communities in the Ny-Ålesund Region, Svalbard (High Arctic). Microbial Ecology 71: 543-554. 